\title{
Corrigendum
}

\section{Mind, brain, and teaching: Some directions for future research-CORRIGENDUM}

\author{
Elena Pasquinelli, Tiziana Zalla, Katarina Gvozdic, Cassandra Potier-Watkins, and Manuela \\ Piazza \\ doi:10.1017/S0140525X14000697, Published online by Cambridge University Press, 8 June 2015
}

The commentator Katarina Gvozdic's surname was incorrectly spelled as Gvodzic in the byline of the commentary by Pasquinelli et al. (2015) on the target article Kline et al. (2015) in Behavioral and Brain Sciences. The name should appear as it does in the byline above. Gvozdic's name has also been corrected in the online version of the commentary.

\section{References}

\footnotetext{
Kline, M. A. (2015) How to learn about teaching: An evolutionary framework for the study of teaching behavior in humans and other animals. Behavioral and Brain Sciences 38:e31.

Pasquinelli, E., Zalla, T., Gvozdic, K., Potier-Watkins, C. \& Piazza, M. (2015) Mind, brain, and teaching: Some directions for future research. Behavioral and Brain Sciences 38: e54. doi.org/10.1017/S0140525X14000697.
} 